\title{
Effects of Teacher Scaffolding on Students' Reading Comprehension
}

\author{
Chanyalew Enyew ${ }^{1}$ and Abiy Yigzaw ${ }^{2^{\star}}$
}

\author{
${ }^{1}$ Faculty of Educational and Behavioural Sciences, Bahir Dar University, Bahir Dar, Ethiopia \\ ${ }^{2}$ Department of English, Faculty of Humanities, Bahir Dar University, Bahir Dar, Ethiopia
}

\begin{tabular}{|c|c|}
\hline Abstract & Article Information \\
\hline \multirow{3}{*}{$\begin{array}{l}\text { This study examined the effects of teacher scaffolding on students' reading } \\
\text { comprehension in Dona Berber Primary School, Ethiopia. Forty-two Grade } 4 \text { students } \\
\text { were selected using purposive sampling. A quasi-experimental pre- and post-test } \\
\text { research design was employed to examine changes in the students' reading } \\
\text { strategies and reading comprehension as a result of teacher scaffolding. Separate } \\
\text { pre-and post-reading comprehension tests, two structured classroom observation } \\
\text { checklists, and Focus Group Discussion were used as data collecting instruments. A } \\
\text { paired samples t-test and percentage were employed to analyze the quantitative data, } \\
\text { but meta-explanations were used to analyse the qualitative ones. The findings } \\
\text { indicated that scaffolding reading strategy instruction is effective in improving } \\
\text { students' passage reading comprehension and teacher's and students' utilization of } \\
\text { scaffolding reading strategies (experiences). Therefore, it is recommended that } \\
\text { training on scaffolding reading strategy use be given to English language teachers } \\
\text { and students in a large scale. }\end{array}$} & \begin{tabular}{ll}
\multicolumn{2}{l}{ Article History: } \\
Received & $: 12-04-2015$ \\
Revised & $: 23-06-2015$ \\
Accepted & $: 25-06-2015$ \\
\end{tabular} \\
\hline & $\begin{array}{l}\text { Keywords: } \\
\text { English as a Foreign Language } \\
\text { First Cycle Primary School } \\
\text { Reading Comprehension } \\
\text { Scaffolding Reading Experience } \\
\text { Strategies }\end{array}$ \\
\hline & $\begin{array}{l}\text { *Corresponding Author: } \\
\text { Abiy Yigzaw }\end{array}$ \\
\hline
\end{tabular}

\section{INTRODUCTION}

The English language is recognized as the most widely used language of communication in this era of globalisation and technology. Hence, teaching English for both adults and children has become crucial in order to help them cope with the dynamic changes and challenges of the current global situation. It is also suggested that the earlier a learner is exposed to the language, the easier he or she learns it (Abiy, 2008; Transitional Government of Ethiopia [hence forth TGE], 1994). One of the mechanisms for enhancing quality of children's learning is improving their reading skill so that it will have pivotal roles in increasing their English language skills (Abiy, 2008; Amlaku, 2010; Eba Mijena, 2014; Gemechis, 2014; Gessesse, 1999; Piper, 2010; TGE, 1994). In order for the English language to serve these roles in education, students' early grade reading comprehension development in the language has become a national concern (American Institutes for Research [hereafter AIR], 2012; Dawit, 2014; Eba Mijena, 2014).

Research has shown that giving the necessary attention to reading strategies becomes important and is taken as the basic rights of children (USAID/GEQIP, 2009). Clay (1990), Juel (1988), Piper (2010) and Stanovich (1986) argue that children who develop reading skills during their earlier years of life would have good reading comprehension throughout their schooling and later in life; and to achieve the skills, teachers should employ successful reading strategies (Oxford, 1997).
There are different approaches to teach reading emanating from different schools of thought or theories: behaviourism to cognitivsm and to social constructivism. In behaviourism, learning to read was left to be dominantly carried on more by the classroom teacher, not by the students (Philips, 1995; Williams, 1984). The behaviourist position was criticized for being mechanistic which focused on recitation. For instance, Vygotsky (1962) criticized behaviourism as being isolated, specialized, too narrow, and intrapersonal in stand point.

On the other hand, cognitivsm pays more attention to memory, information processing approaches, attention and noticing. Both the theories were vehemently criticized for overlooking the social context of learning. Social constructivism focuses on the social factors in the process of learning, stating that learning is not an individualistic process. Rather, it needs to be learned in a social context with the help of capable peers, parents or expert teachers (Vygotsky, 1978).

It assumes that students better learn subjects and reading comprehension with the help of capable adults, parents, teachers or peers. In this theory, therefore, scaffolding is a prerequisite for reading development to take place appropriately (Lantolf and Thorne, 2006). The concept of scaffolding is highly related with Vygotsky's Zone of Proximal Development (ZPD), the central concept in socio-cultural theory (Clark and Graves, 2004), that elaborates the important role of teachers as mediators. Recent research results recommend the use of 
scaffolding reading strategies as having a facilitative role when it is connected and practiced with reading comprehension. So, the relationship between teacher scaffolding reading strategies and student reading comprehension in primary reading classrooms has increasingly attracted attention of reading experts in recent years (Fitzgerald and Graves, 2004; National Reading Panel, 2000). However, in EFL classroom setting reading seems scant in primary grades; scaffolding students to read successfully is thus imperative.

Teacher scaffolding helps students improve their passage reading comprehension. It is suggested that scaffolding be used as a temporary interactional process between teachers and students until students become autonomous readers. This means that the more students get familiarized with their learning, the less the application of scaffolding would be (Vygotsky, 1978, 1986). Wood, Bruner and Ross (1976) defined scaffolding, as a process that "enables a child or novice learner to solve a task or achieve a goal that would be beyond his unsatisfied efforts" (p. 90). This definition emphasizes the collaborative effort of the teacher with the students in constructing knowledge, the teacher supporting the student.

There are arguments that a certain level of classroom teacher's scaffolding backed-up by reading strategies can help primary grade students improve their passage reading comprehension (Abiy, 2008; Rodgers and Rodgers, 2004). Williams (1984) stresses that the most important part of teacher's job is to support students develop appropriate strategies for reading. In other words, the teacher is responsible to empower students to create their own meaning by combining linguistic and cultural components and drawing meaning from their experiences while reading a text. To this end, teacher scaffolding which is intentionally designed and carefully taught seems to be fundamental so that students can become independent and self-regulated life-long readers (Chi, 2007).

Studies conducted by Chi (2007), Hammond (2002) and Snow, Burns and Griffin (1998) show that scaffolding is a crucial role of teachers, knowledgeable adults, parents, guardians or more knowledgeable peers in guiding students' reading skills and re-conceptualizing learners' output to push not only language development and proficiency but also cognitive gains which will help them be autonomous learners. Harmer (2003) stressed the various roles of the teacher in teaching reading of which improving students reading by exposing students to reading strategies is the most essential ingredient in developing other skills and reading as a foundation. Taylor, Pearson, Clark and Walpole (2000) disclose that scaffolding reading strategy is regularly used only by a few teachers. Scharlach (2008) also was found that reading skills' instruction is much less frequent than it ought to be. Teachers' support in enhancing students' reading skill is not at its best and complete although there is almost consensus that scaffolding plays a significant role in improving reading comprehension (Rodgers and Rodgers, 2004).

Different from the traditional view of reading as a purely individualistic skill, based on the socio-cultural theory of learning, reading has been looked from a completely social perspective, which points up active participation and interaction of learners. Accordingly, the current study is an attempt to show the potential use of scaffolding strategies in improving EFL students' reading comprehension.

Rodgers and Rodgers (2004) note that although the issue of early grade reading instruction has been an important part of research on reading skills and strategies, it was overlooked in favour of secondary school reading research. Hence, it could be argued that improving primary level students' poor reading comprehension in the English language had not been duly considered or taken care of.

The problem of using English across the curriculum still continues to be acute. Abiy (2008) and Michael (2003) argue that the problem of low capability of teachers in teaching English language reading is prevalent at all levels of education. Dereje (2012) also comments that First Cycle Primary School (Grades 1-4) teachers' English language proficiency and English teaching skills are too weak to implement the tasks and activities embedded in the English textbooks. Eba Mijena (2014) examines the practices and challenges in teaching of English to young learners in selected ten first cycle (Grades 1-4) public primary schools of Nekemte Town, Ethiopia. He discloses that teachers used to teach in students' mother tongue dominantly because of their poor command of the English language. Teachers' low capacity in the English language was attributed to lack of the necessary pre- and in-service professional development courses, which implies the necessity of teacher training on scaffolding strategies. Gemechis (2014), in his investigation of whether or not teachers employed an effective reading techniques and how the students accessed reading materials in some selected second cycle primary school (5-8) of Oromia region, Ethiopia, has also found out that the most serious problems identified in teaching reading were the less applicability of appropriate reading techniques by teachers and lack of relevant reading materials for students.

On the other hand, as different studies have indicated, primary school students exhibited low performance in reading. For example, a study on Ethiopian primary schools' reading classes revealed that students were hardly engaged in practice and drill, where teachers mostly taught through lecturing (Moore, DeStefano, and Adelman, 2010). In addition, the Baseline National Learning Assessment (BNLA) undertaken by National Organization for Examinations (NOE, 2000), the Second National Learning Assessment (SNLA: NOE, 2004), and the Third National Learning Assessment (TNLA: Ministry of Education [MoE], 2008) conducted showed that there are clear reading deficiencies among students. The main objective of the national learning assessments was to determine what primary school students achieved upon completion of first cycle (Grade 4) and second cycle (Grade 8) in light of the minimum learning competencies set by the Ministry of Education. The result showed that students' performance was deteriorating. For instance, TNLA (conducted in 2008) disclosed that students' reading comprehension achievement remarkably decreased $($ mean $=43.9$ ) from the result obtained during the BNLA (mean=64.3). Particularly, the 2008 TNLA's breakdown of scores by subjects indicated that about $51.7 \%$ of the students scored below "basic" (a score of $50 \%$ ) on reading comprehension. This means that there is 
a continuous decrease in Grade 4 students' reading achievement which needs further study and intervention.

Besides, the Ethiopian English Early Grade Reading Assessment conducted by AIR (2012) that tested reading skills of students who had completed grades 2,3 , and who joined grade 4 involving all nine regions and two city administrations in the assessment, also showed low student results. The preliminary results disclosed that about two thirds of the students who were tested were not able to demonstrate the knowledge and skills expected by the MoE's (2008) curriculum minimum learning competencies (AIR, 2012; Piper, 2010).

Furthermore, Tsehay's (2013) study in Amhara Region of Semein Gonder Zone Primary Schools on reading shows that students' early reading achievement is low. The children in KGs and first grade displayed very small levels of pre-reading skills. The evidence collected indicates that the majority of the children, even those at the later stages of first cycle primary schooling, were unable to display proficiencies in reading skills such as letter naming and phonemic awareness abilities. The word reading and paragraph reading fluencies were too much below the minimum expectations; i.e. the children's reading ability was very low gauged against the expected reading competences indicated by grade level (MoE, 2008). The deficiencies with comprehension questions were chronic. Out of the 7 comprehension questions asked, they scored a mean of 1.7 , the rest $38 \%$ scoring zero. The results appear to be similar with previous assessments (AIR, 2012; Dereje, 2012; Gemechis, 2014; Piper, 2010) implying that the problem is continuing. He concludes that even $4^{\text {th }}$ grade students, who are about to complete the first cycle primary schooling could read only an average of $27 \mathrm{wpm}$ and the rest $7 \%$ of the group missing all. The mean of nonsense words reading was 19 wpm, $13 \%$ of them scoring zero. Hence, 'reading' is suffering from deficiencies of trainings and consequent decreases in primary school teachers' and their students' ability to read at a basic level which needs further studies and endeavour (Abiy, 2008; AIR, 2012; Piper, 2010; Smith, Stone and Comings, 2012; Tsehay, 2013).

Thus, there is a concern that the existing reading instruction approach in primary schools in Ethiopia is helping students only little to improve their reading comprehension (Piper, 2010). Referring to primary school students' current status of reading skills, it is recommended in the USAID/Ethiopia study that systematic interventions targeting reading instruction and the provision of reading materials are essential (AIR, 2012; Piper, 2010). It is mainly suggested that reading strategy training for teachers on how to appropriately and successfully teach reading strategies to children is necessary. This, in fact, implies the need for training of teachers for primary schools in early grade reading strategies in order to facilitate students' reading skills strategy and engagement in reading. That is why this study was intended to intervene on primary school English language reading lessons, particularly focussing on grade 4.

As stated above, few studies on Ethiopian English language reading have been conducted at primary first cycle (Chefena, 1988; Dereje, 2012; Eba Mijena, 2014; Mesfin, 2008; Zenebe, 2000) and second cycle (Micheal, 2003; Gemechis, 2014) schools. However, to the knowledge of the researchers, there were no studies that addressed teacher scaffolding reading strategies to improve students' reading comprehension in Ethiopian first cycle primary schools (Grades1-4). Besides, informal discussions held with Amharic and English language teachers, personal experiences as university professors, observations during the practicum supervision and preliminary observations made on Grade 4 EFL classes at Ewket Fana, Kulkual Meda, Dona Berber and Addis Amba Primary Schools, in Bahr Dar City by the researchers have revealed shortcomings on investigations of reading strategies, particularly teacher scaffolding as a strategy; and this, we trust, requires further investigation. Hence, this study aims at investigating teacher scaffolding strategies intervention as a means of improving students' reading comprehension skill among grade 4 students. Based on this objective, the study has attempted to respond to the following research question.

- What is the effect of scaffolding reading strategy instruction on Grade 4 students' passage reading comprehension of?

It is hoped that the findings of the study could help both teachers and students construct a deeper understanding of scaffolding in EFL reading, use it more frequently in their classrooms, and thereby improve students' passage reading comprehension.

\section{METHODOLOGY}

This study attempted to investigate the effects of scaffolding reading strategies on grade 4 students' passage reading comprehension in one government Primary School at Bahr Dar, Ethiopia. The study employed a quasi-experimental pre- and post-test research design to examine changes in the students' reading strategies and reading comprehension as a result of teacher scaffolding. A quasi-experimental research design was chosen because the researchers deemed this design would allow them to use intact classroom setting in which random assignment of participants of the study to different conditions was not a mandatory (Creswell, 2009). Hence, this study applied an intact classroom by taking one section of Grade $4(\mathrm{~N}=42)$ students to look into whether or not the teacher scaffolding instruction improves students' English passage reading comprehension.

\section{Instruments}

\section{Passage Reading Comprehension Tests}

In Ethiopia, there are no available standardized tests that could measure passage reading comprehension of primary school students except the Ethiopia English Early Grade Reading Assessment (EEEGRA) used by American Institutes for Research [AIR] (2012) and mother tongue EGRA by Piper (2010). Both AIR (2012) and Piper (2010) levelled the assessments according to the MOE's Minimum Learning Competencies. AIR (2012) piloted reading skills test instruments for grades 2-4 and implemented on 19,800 randomly selected grade 2-4 students in 330 randomly selected schools drawn from the nine regions and two city administrations in Ethiopia. For this research, a few elements of reading comprehension were adapted and used to construct one pre-test and one post-test teacher made tests by two Grade 4 English language teachers for passage reading comprehension. Attempts were made to construct both valid and reliable tests. Care was taken to follow the familiar formats and test procedures of the school and the students. The 
allotments of the time, the value of the tests and instructions on how to read the passages were given clearly. Attention was paid to make sure that the difficulty level of words was appropriate to MoE (2011)'s English for Ethiopia Grade 4 Student Book. The passages used to prepare the pre-test and post-test items had also similar level of difficulty in terms of words, length of passage and text structure with that of the Grade 4 English textbook texts for reading to meet the appropriate grade level readability for the students.

\section{Classroom Observation Checklist and field notes}

A structured/closed-item observation checklist with eight items having a "Yes" or "No" response was adapted from teacher's roles and lesson templates fidelity checklists of Butler (2007), Donaldson (2011), Fitzgerald and Graves (2004) and Harmer (2003) to see how reading strategies were employed. Thus, eight round observations were conducted by the researchers and checked and rated how the teacher implemented scaffolding reading strategies while teaching reading comprehension.

\section{Checklist for Students}

The intervention of Scaffolding Reading Experience (SRE) checklist that contains six scaffolding reading strategies was filled by students for analysis. The students' checklist wanted to get information about their reflections of the daily lesson. The checklist had two rating scales: (2) "Yes" or (1) "No"; and it was filled by the students in each reading lesson. The percentage score of responses on each strategy lesson was calculated.

\section{Focus Group Discussion (FGD)/ Reflection}

Eventually, focus group discussions were held with teachers and students. The discussions focussed on three major points that incorporate how teacher scaffolding of reading strategies had been implemented during reading classes, what benefits the students have gained and what should be done to improve the program. The data obtained from the FGD were analysed qualitatively.

\section{Procedures}

The researches have employed the following procedures concerning instructional material and training of the classroom teachers, the FGD, and the other instruments used in the study.

Having secured permission from the school's vicedirector, the director, the department head and the classroom teacher, the researchers started the training on the classroom teacher's scaffolding of reading instruction. The teacher's scaffolding of the reading strategy intervention was planned to be implemented by one Grade 4 regular classroom teacher and her assistant. It is recommended that prior to the intervention introducing the scaffolding of reading strategy instruction to the teachers and encouraging them to apply in their lessons is vital (Butler, 2007; Donaldson, 2011; Fitzgerald and Graves, 2004; Harmer, 2003). Hence, a training manual that could be covered in eight hours was prepared by the researchers. During the training, practical scaffolding of reading strategy training supported by trainee reflection and trainer feedback was given for the regular teacher assigned to teach the selected class and one reserve teacher was also trained to substitute the regular teacher in case of emergency. Training the two teachers created a collaborative and interactive scenario during the training. The training was given by the researchers of this study.
Exemplary and demonstrative samples were given to the teachers on why, what, and how of the scaffolding of reading strategy throughout different units of reading passages. This was done to insure that the scaffolding reading strategy might be implemented regularly and actively during the actual reading classes by the classroom teacher.

In this study, the Scaffolding Reading Experience (SRE) model was selected as an instrument for intervention as it encompasses all the necessary scaffolding reading strategies for EFL learners at all grade levels. These scaffolding strategies are the pre-duringpost-reading strategies. In pre-reading phase, introducing the title/topic of the story, giving direction, making logical predictions, setting purpose for reading, pre-teaching new, key, difficult words, connecting background knowledge, using student native language and describing reading strategy are incorporated. The during reading strategies include teacher loud reading, student loud reading, student silent reading, answering and asking questions and using strategies in self/independent reading. And the after (post) reading strategies comprise of using questions to interpret, analyze, evaluate, and promote higher-order thinking, using graphic organizers to recall information, answering questions and summarising the story using their native language and independent use of the strategy.

In order for the trainees to get well acquainted with Scaffolding Reading Experience (SRE), on the first day of the training, the researchers introduced the SRE to the teachers as one of the useful reading strategies in improving students' passage reading comprehension. The time set for the training was three hours. It was started by introducing to the teachers the rationale and the pre, during-and post-reading strategies involved in SRE. The training manual was provided to the two teachers. From Grade 4 Student Text (MoE, 2011), one passage on page 31 of unit 3, "Anito", was selected during the first day and each of the SRE phases was first introduced through gapped-lecture, explanation, thinking aloud demonstration, and discussion. Then, trainer-trainee discussion and reflection was accompanied by trainees' comments for improvement. Based on the feedback, the next round trainings were planned.

In the next two round trainings (for 2:30 hours session each), the teachers continued practicing the SRE using the selected texts in the Teacher's guide and the Grade 4 textbook of units four, five and six. Teachers were encouraged to apply the SRE and discuss each other how to apply SRE in reading classes. After answering each question in the exercise of the manual and the textbook, teachers were then invited to exchange their notebooks to help them check what and how they did.

From the SREs, the current study is limited to the following strategies. For pre-reading phases introducing the title/topic of the story, prediction, pre-teaching of new vocabulary, activating background knowledge, using students' native language, and describing strategy were used. For the while/during reading stage teacher loud reading, engaging students in individual/paired loud and silent reading, think aloud, and silent independent reading were used. In after (post) reading session, questioning, graphic organizer to recall/summarize information, summarizing the story in students' native language $\left(L_{1}\right)$ and student engagement in strategy use were applied. 
This model (SRE) was used as it is helpful to design a detailed reading lesson plan in order to teach the contents of passage reading comprehension. Therefore, the teachers were trained to apply the SREs the following way. In the pre-reading stage, teachers were encouraged to activate background knowledge. In the during/while reading, teachers practised how they would teach teacher loud reading, student loud reading, student silent reading, answering and asking questions and using strategies in self/independent reading. And during the post reading, they practised how to encourage students and how to reread and help each other and read independently. Generally, teachers were trained in all the sessions how they could plan and apply the SRE in their daily reading lessons and activities. The trainees were also introduced to apply the lesson plan templates developed by Butler (2007) and Harmer (2003).

Regarding tests, the researchers developed multiplechoice pre-and post-reading comprehension tests to measure the students' reading comprehension. A short reading text (a paragraph) [each for the pre-and posttests] of equivalent length (60 words each) was given to the students to gauge their reading comprehension. Different types of comprehension questions that constitute low and high order levels were prepared for the purpose. The teachers classified the test questions in to two comprehension levels; that is, lower order and higher order questions in the form of true-false, vocabulary and multiple-choice reading comprehension items. Both tests have clear instructions on each item having one mark for each question answered with a total of $15 \%$ marks. A pretest was given individually to each Grade 4 student $(\mathrm{N}=42)$ of Dona Berber Primary School by two EFL teachers before the intervention had begun and the posttest was given after the intervention was done by the same teachers.

The students had to fill in the checklist meant for them after each lesson so that they can reflect about the daily lesson. This was aimed to see how adequately students practiced Scaffolding Reading Experience (SRE) during the whole lessons and determined the extent to which the use of SRE strategy has improved students' passage reading comprehension as the lesson progressed. Similarly, the researches filled the checklist that provides information about what was going on all through the lesson: during pre-while and post-reading stages. The researchers also filled in the checklist to see how the teacher applied the SRE during the pre-, while and postreading stages.

\section{Data Analyses Techniques}

The data obtained from the observation checklist was analyzed using percentage, while the comparison of the students' pre- and post-test results was computed using independent samples t-test. The information secured through the FGD was qualitatively analyzed using metaexplanation

\section{RESULTS}

The study disclosed its results in four sections. A brief description was given in the first section about the implementation of the study related to the scaffolding reading strategy training for the teacher. The second section showed reading comprehension test results of the students on the pre- and post-tests. The third section presented student questionnaire. The fourth one disclosed researchers' observation results on teacher scaffolding strategy along with teacher and student reflection.

\section{Implementing the Intervention}

The Scaffolded Reading Experience model was adapted and used based on the guidelines of Fitzgerald and Graves (2004). Before starting the intervention, training was given to the teacher by the researchers. And the teacher trained the students on the strategies to be used in the study. Then, the treatment was given after a pre-test was conducted once on students' oral reading fluency for a single group of 42 students. The grade 4 teacher told students about the application of reading strategies in the three phases, i.e., before, during and after phases and the activities of reading.

On the first day, the teacher explained the objectives and demonstrated the scaffolding reading strategies to the students how, when, and where these strategies could be applied. Each scaffolding phase was explained to the students and a three page list of the strategies written by the teacher was provided to each student and fixed on the wall. The teacher first introduced the reading tasks in accordance with the reading strategies followed by teacher-student interaction, student-student interaction and independent practice of the scaffolding reading strategies. Then, they applied the strategies.

\section{Reading Comprehension Test Scores}

The mean scores of students' on the pre-test and posttest are shown in Table 1. To measure the changes students attained through the intervention, a paired samples t-test was calculated for their pre- and post-test results.

Table 1: Paired samples t-test for students' pre-test and post-test reading comprehension scores

\begin{tabular}{ccccccc}
\hline Test & N & Mean & Std. Deviation & t-value & Df & Sig. (2-tailed) \\
\hline Pre & 42 & 13.8571 & 5.85004 & 12.00 & 41 & $0.000^{* *}$ \\
Post & 42 & 20.1429 & 5.74911 & & & \\
\hline \multicolumn{5}{c}{${ }^{* \star} P<0.01$} \\
\end{tabular}

Table 1 above shows that scaffolding intervention has improved students' passage reading comprehension scores significantly $(\mathrm{t}=8.567, \mathrm{P}=0.000)$ at the level of $\mathrm{P}<$ 0.01 in favour of the students' post test reading comprehension scores. The increment in reading scores might have been gained due to the intervention, which involved teacher and student engagement. Strong significant differences were exhibited in the students' post-test reading comprehension; and this supports the claim that employing scaffolding can improve passage reading comprehension skills.

The results disclosed that there were significant improvements in the students' passage reading comprehension scores over time. The finding is consistent with Dawit's (2014) and Kim and White's 
(2008) results which show the students in the intervention with explicit teacher and parent scaffolding reading strategies demonstrated consistent improvement on reading passage comprehension.

\section{Teacher Scaffolding Strategy use in Reading}

Item 1 in the Table above disclosed that the teacher introduced the title to the students at the beginning of all the reading lessons. The classroom observation also displayed that the strategy was applied both by the students and the teacher. The students' response of their reading lesson experiences indicated that their teacher highly encouraged their prediction $(91.6 \%)$ while reading passages. Students have witnessed that the teacher teaches them vocabulary $(90 \%)$ before they have read passages. The teacher also activates the application of individual loud reading $(97.7 \%)$ and silent reading $(71.4 \%)$ strategies, of course with varied degrees. The finding also unravelled that the teacher has motivated students to use their native language $\left(L_{1}\right)$. The students were also motivated to apply questioning strategy $(85 \%)$ and summarizing a story $(90 \%)$. From the above results, one can infer that the teacher overall applied reading strategies regularly; however, the result showed that her intervention varied from strategy to strategy; the highest being pre-taught vocabulary $(100 \%)$ strategy, and the least being silent reading $(71.4 \%)$ strategy.

Table 2: Students' responses on teacher scaffolding strategy use in reading $(\mathrm{N}=42)$

\begin{tabular}{|c|c|c|c|c|}
\hline \multirow{2}{*}{ Item } & \multirow{2}{*}{$\begin{array}{l}\text { Strategy applied by } \\
\text { theTeacher. }\end{array}$} & \multicolumn{3}{|c|}{ Students' response } \\
\hline & & Item & No. & $\%$ \\
\hline \multirow{3}{*}{1} & \multirow{3}{*}{ introduced title. } & Yes & 42 & 100 \\
\hline & & No & - & - \\
\hline & & Total & 42 & 100 \\
\hline \multirow{3}{*}{2} & \multirow{3}{*}{ invited for prediction. } & Yes & 39 & 91.6 \\
\hline & & No & 3 & 8.4 \\
\hline & & Total & 42 & 100 \\
\hline \multirow{3}{*}{3} & \multirow{3}{*}{ pre-taught vocabulary. } & Yes & 40 & 90.5 \\
\hline & & No & 2 & 9.5 \\
\hline & & Total & 42 & 100 \\
\hline \multirow{3}{*}{4} & \multirow{3}{*}{$\begin{array}{l}\text { activated think aloud/ } \\
\text { loud reading. }\end{array}$} & Yes & 41 & 97.7 \\
\hline & & No & 1 & 2.3 \\
\hline & & Total & 42 & 100 \\
\hline \multirow{3}{*}{5} & \multirow{3}{*}{$\begin{array}{l}\text { encouraged silent } \\
\text { reading. }\end{array}$} & Yes & 30 & 71.4 \\
\hline & & No & 12 & 28.6 \\
\hline & & Total & 42 & 100 \\
\hline \multirow{3}{*}{6} & \multirow{3}{*}{$\begin{array}{l}\text { encouraged } L_{1} \text { use for } \\
\text { summary. }\end{array}$} & Yes & 42 & 100 \\
\hline & & No & - & - \\
\hline & & Total & 42 & 100 \\
\hline \multirow{3}{*}{7} & \multirow{3}{*}{ motivated questioning. } & Yes & 36 & 85.7 \\
\hline & & No & 6 & 14.3 \\
\hline & & Total & 42 & 100 \\
\hline \multirow{3}{*}{8} & \multirow{3}{*}{ activated summarization } & Yes & 38 & 90.4 \\
\hline & & No & 4 & 9.6 \\
\hline & & Total & 42 & 100 \\
\hline
\end{tabular}

\section{Teacher's Strategy use as Observed}

Table 3 shows the same results with Table 1on introducing the title (Item 1) and encouraging $L_{1}$ (Item 6) use for summary. Items 2, 3, 7 and 8 also show closer frequency usage with a slight difference from items 4 and 5 . The classroom observation checklist and field note of the researchers indicate that the teacher first introduced the reading tasks in accordance with the reading strategies followed by teacher-student interaction, student-student interaction and independent practice of the scaffolding reading strategies.
On the first day, the teacher demonstrated objectives of the scaffolding reading strategies to the students how, when, and where these strategies could be applied. Each scaffolding phase was explained to the students and a three page list of the strategies written by hand visibly was posted on the wall. And a one page summary of the strategies was given to each student for independent practice. One sample paragraph (unit three, "Anito") was chosen from the student textbook and the teacher explained on how and when to use the strategy by modelling each phase of the strategies through topic introduction, prediction, think aloud and discussion. The teacher is expected to prompt students to use the strategic processes regularly. In the first and second lessons, both the teacher and the students were reluctant to properly apply the strategies. Even the teacher was not modelling prediction (item 2), silent reading (item 5) and questioning (item 7) strategies during the before, while and post-reading stages. Particularly, during the first and the second lessons, students were unable to use silent reading strategy. They did not even effectively finish in the allocated time; and therefore, the teacher was obliged to focus on students' reading aloud. But, during the next lessons, students were encouraged and reminded of how to apply the strategies in their reading lessons which were carried out for a lesson (each lesson for one hour) that covered four weeks. Then, they were able to apply the strategies to some extent.

During the while reading stage, the teacher introduced title, encouraged prediction, modelled loud reading followed by student oral and silent reading, choral reading, paired-reading, guided reading and independent reading. She modelled teacher loud reading to facilitate appropriate spelling, and pronunciation. Students were taught passage reading through loud and silent reading to facilitate higher order thinking among the students.

In the post reading strategy stage, the teacher motivated the students to practice pair/group reading where the students were arranged to sit in pairs/groups and shown how to use the short paragraph with the reading strategies' list. One student from the group would read to the group members and others would give corrections to ensure the speed with accurate pronunciation and meaning of difficult words. Then, the teacher would invite the students to read orally and silently. Next, the teacher guided and assisted the students in their use of the strategy. The teacher would make rounds and give individual supports when needed. Finally, the teacher invited the students to reread individually to improve their comprehension of the text they read. She mostly gave reading assignments by the end of the period and encouraged students to read to the class the following period before she began the daily lesson. In the $8^{\text {th }}$ reading class, the teacher and students were observed to follow flexible kind of reading strategies as necessary by the end of the intervention.

Besides, examining the results of teacher observation on each strategy aforementioned in the eight lessons revealed that students showed better improvement However, field note of the researchers disclosed that students were not equally performing in all the scaffolding reading strategies. 
Table 3: Classroom observation results on strategy use

\begin{tabular}{|c|c|c|c|c|c|c|c|c|c|c|c|}
\hline \multirow[t]{2}{*}{ No } & \multirow[t]{2}{*}{ Teacher } & \multicolumn{10}{|c|}{ Occurrence of behaviour } \\
\hline & & Obs.1 & Obs.2 & Obs. 3 & Obs. 4 & Obs.5 & Obs. 6 & Obs.7 & Obs. 8 & Total & $\%$ \\
\hline 1 & introduced title & $\mathrm{X}$ & $\mathrm{X}$ & $\mathrm{X}$ & $\mathrm{X}$ & $\mathrm{X}$ & $\mathrm{X}$ & $\mathrm{X}$ & $\mathrm{X}$ & 8 & 100 \\
\hline 2 & invited for prediction & - & - & $\mathrm{X}$ & $\mathrm{X}$ & $X$ & $\mathrm{X}$ & $x$ & $X$ & 6 & 75 \\
\hline 3 & pre-taught vocabulary & - & $\mathrm{X}$ & $X$ & $\mathrm{X}$ & $\mathrm{X}$ & $\mathrm{X}$ & $X$ & $\mathrm{X}$ & 7 & 87.5 \\
\hline 4 & activated think aloud/loud reading & - & $\mathrm{X}$ & $\mathrm{X}$ & - & $\mathrm{X}$ & $\mathrm{X}$ & $X$ & $\mathrm{X}$ & 6 & 75 \\
\hline 5 & encouraged silent reading & - & - & $X$ & - & $X$ & $X$ & $X$ & $X$ & 5 & 62.5 \\
\hline 6 & encouraged L1 use for summary & $X$ & $\mathrm{X}$ & $X$ & $\mathrm{X}$ & $\mathrm{X}$ & $\mathrm{X}$ & $\mathrm{X}$ & $\mathrm{X}$ & 8 & 100 \\
\hline 7 & motivated questioning & - & - & $\mathrm{X}$ & $\mathrm{X}$ & $\mathrm{X}$ & $x$ & $x$ & $\mathrm{X}$ & 6 & 75 \\
\hline 8 & activated summarization & - & $\mathrm{X}$ & $X$ & $X$ & - & $\mathrm{X}$ & $X$ & $\mathrm{X}$ & 6 & 75 \\
\hline
\end{tabular}

Furthermore, the teacher's and students' reflection pointed out that students' passage reading comprehension on the 'student independent strategy use' and 'individual silent reading' strategies were somewhat lower than on the 'teacher modelling' and 'student reading aloud'. This might have occurred because independent strategy use and individual silent reading demanded students' to use higher level thinking and getting meaning from the passage without the support of the teacher. In addition, the applications of the scaffolding strategies were very much demanding. However, as evidenced in this research, even short-term scaffolding intervention which lasted in 8 weeks showed encouraging improvements on students' passage reading comprehension.

It seems that more scaffolding is needed to boost students' passage reading comprehension. The participating students reflected that they are beneficiaries because they have improved reading comprehension and strategy use. The teacher also appreciated teacher scaffolding as effective instrument and shared the same idea with the students except her comment on use of much time. She said, "Application of scaffolding is time consuming". Both the teacher and the students appreciated scaffolding intervention. They said they had doubts about the continuity of the program and stressed on the continuation of the intervention.

Teacher's and students' reflection in the FGD showed the following results.

Teacher: The English teacher expressed that she noticed improvements in students' prediction skills gradually. Specifically, predictions were more relevant to stories as time progressed during the intervention period. More accurate prediction, according to the instructor, signified an increase in student reading comprehension. For example, students' predictions seemed to be very confused. In the beginning, they elicited all what they felt.... After we went to the end they were able to pick up fast and they really, were proud every time that they made a good prediction.

Student 1: An advantage of teacher scaffolding was that it allowed us to build confidence bout reading comprehension, and enhance our self-confidence.

Teacher: Scaffolding not only prompted student interaction but also created a venue for students' shared native language as a resource. For instance, a student who had very limited English comprehension reading, and kept silent at the beginning, was able to express her opinions in Amharic assisted by her group members and the teacher. Her gradual progress from silence to her first language (Amharic), from first language to English language, is another great example of scaffolded reading experience to success.
Student 2: Our teacher assisted me to connect prior knowledge, made predictions, and set for purpose for reading before I started reading.

Teacher: During reading, I stop students and ask them to tell me what they are thinking.... as a part of guiding them to recognize when they are not comprehending. I also invite them to retell or summarize what they have read and show improvement.

From the above reflections, it could be argued that the teacher scaffolding showed improvement in students independent reading comprehension because students felt capable of reading difficult words successfully. The words used in the passages were familiar with the students' surroundings they encounter in their daily lives which enhanced their motivation to read their textbook more.

To sum up, at the beginning of the intervention, the students had difficulty of using the strategies, because the strategies were new for them. However, after the 2 lessons, students started utilizing the strategy while reading the texts. Particularly, at the beginning of the intervention, the teacher was not highly involved in helping the students apply the strategy and providing guidance to some students when they needed. Besides, the classroom observation of the researchers during the intervention and reflections of the students and the teacher strengthened that they had keen interest and motivation after wards. By the end of the intervention, it was observed that a large majority of the students were actively engaged in reading comprehension texts.

\section{DISCUSSION}

The purpose of this study was to find out the effects of teacher scaffolding on Grade 4 students' passage reading comprehension at Dona Berber Primary School. One pretest and one post-test similar in time allotment, length of paragraph, closer in content, question type, and number of questions were administered to check whether or not the scaffolding reading strategy has brought improvements on students' passage reading comprehension. Analyses of pre-post test scores indicated that there was a significant difference in passage reading comprehension scores. Analyses of students' responses during each lesson also indicated that students have demonstrated gradual and steady improvement in their passage reading comprehension. This finding is consistent with previous studies, which pointed out the use of teacher scaffolding reading strategy instruction has resulted in an increased reading comprehension skill of the students (Butler, 2007; Dawit, 2014; Karim and Jallivand, 2014; Kim and White, 2008). Actual classroom observations in the intervention also made clear some evidence about the possible reasons that resulted in the improvement of student reading 
comprehension scores and strategy use. At the beginning of the teacher scaffolding intervention, student-teacher engagement was limited. However, the intervention has created conducive situation to the teacher and the students to stay engaged in cooperation on the reading tasks. Whenever the teacher introduced the strategies, students were able to apply them in their passage reading comprehension. Later, the role of the teacher was replaced by students' responsibility and students were busily engaged in activities in pairs, in groups, on studentstudent supports, feedback and independent reading. Previous research has shown that when a teacher creates learning environments that enable reading engagement to be continuous and conforming to students' level, their reading comprehension increases (AIR, 2012; Dawit, 2014; Karim and Jallivand, 2014; Kim and White, 2008).

\section{CONCLUSIONS}

Based on the findings, it is possible to conclude that teacher scaffolding reading strategy instruction significantly improved students' passage reading comprehension in first cycle primary schools. This finding is consistent with previous studies, which pointed out the use of scaffolding reading strategy instruction has resulted in an increased reading comprehension of the learners (Butler, 2007; Dawit, 2014; Karim and Jallivand, 2014; Kim andWhite, 2008; Mesfin, 2008).

This quasi-experimental research was conducted to see whether or not teacher's scaffolding reading experiences (strategies) improve students' reading comprehension skill. The findings indicated that the students' reading comprehension skill was improved using scaffolding reading strategies. Therefore, it was concluded that the scaffolding reading experiences (strategies) are significant for the students' development of their reading comprehension and strategy. Although improvements were observed in students' reading and strategy use, their results indicated that further attempt seems to be mandatory to reasonably develop their strategy in reading comprehension. Based on the findings and the conclusion, it was recommended that teacher intervention using scaffolding strategies' instruction is desirable; thus, we suggest reading teachers apply it in their reading classes. In addition, students need more opportunity to reading and moderately challenging tasks to develop their reading comprehension skill and their strategy use. Finally, it is suggested that future research with extended intervention period and larger sample size at different grade levels be conducted. The research needs to include other data gathering instruments with more sample size and more strategy use. Eventually, there should be training on scaffolding reading strategy use for the English language teachers, students and school leaders to make the reading lesson student friendly and engaging.

\section{Conflict of Interest}

Authors have no conflict of interest

\section{REFERENCES}

Abebe Damitew (2012). Teaching reading skills in English as a foreign language through interactive classroom teaching versus plasma teaching with reference to Grade Ten Students in Addis Ababa (unpublished PhD Dissertation): Addis Ababa University.
Abiy Ygzaw (2008). Effects of teacher mediation on students' conceptions and approaches to reading. (Unpublished PhD Dissertation): Addis Ababa University.

American Institutes for Research (AIR). (2012). Ethiopia Teach English for Life Learning (TELL) Program Field Study Report Policy and Practice in Ethiopia Building on the TELL Program and EGRA Results. USAID Ethiopia.

Amlaku, B. (2010). Language policies and the role of English in Ethiopia. A PresentationPaper at the $23^{\text {rd }}$ Annual Conference of IATEFLBESIE(19-21), Bielefeld, Germany.

Butler, T.W. (2007). Vocabulary and comprehension with students in primary grades: A comparison of instructional strategies (unpublished PhD Dissertation), University of Florida.

Chall, J. (1983). Strategies for Reading Development. New York: McGraw-Hill.

Chefena Hailemariam. (1988). An Investigation of the Practices of Beginning Reading instructions in Government and Public Elementary Schools in Addis Ababa. (unpublished M.A. Thesis), Addis Ababa University.

Chi, Feng-ming (2007). Scaffolding EFL Learners' Reading Comprehension of Texts. Department of Foreign Languages and Literature, National Chung Cheng University, Taiwan.

Clay, M. (1990). The Early Detection of Reading Difficulties. Hong Kong: Heinemann

Clark, K., and Graves, M. (2004). Students' Comprehension of Text. Reading Teacher 58(6): 570-580.

Cohen, L., Manion, L. and Morrison, K. (2007). Research Methods in Education (6 ${ }^{\text {th }}$ ed.) U.S.A: The Taylor and Francis e-Library.

Creswell, J.W. (2009). Research Design Qualitative, Quantitative, and Mixed Methods Approaches (3rd ed.). Thousand Oaks, CA: Sage.

Dawit Tibebu (2014). The effects of explicit reading strategy instruction on reading comprehension of upper primary grade students. International Journal of Education 6(3): 1-20.

Dereje Negede. (2012). Primary EFL Teaching in Ethiopia: Policy and Practice; (Unpublished PhD Dissertation), Addis Ababa University.

Donaldson, R (2011). What Classroom Observations Reveal About Primary Grade Reading Comprehension instruction within High Poverty Schools Participating in the Federal Reading First Initiative. http://digitalcommons.usu.edu. letd/987.

Eba Mijena (2014). Practices and impeding factors in the teaching of English to young learners in the First Cycle Public Primary Schools at Nekemte Town, Western Ethiopia.' Science, Technology and Arts Research Journal 3(2): 201-212.

Fitzgerald, J. and Graves, M.F. (2004). Scaffolding reading experiences for English-language learners. Norwood, MA: Cristopher-Gorden Publishers, Inc.

Gemechis Teshome (2014). Teaching reading skills in second cycle (5-8) of primary school in Oromiya Region: focus to East Wollega and Illuababor Zones. International Journal of Sciences: Basic \& Applied Research (IJSBAR) 17(1): 95-109.

Gessesse Tadesse (1999). The Effect of a process Approach to Teaching Reading on First Year Students at Kotebe College of Teacher Education (Unpublished PhD Dissertation), School of Graduate Studies. Addis Ababa University. 
Chanyalew Enyew and Abiy Yigzaw

Hammond, J.E. (2002). Scaffolding Teaching and Learning in Language and Literacy Education. Newtown, Australia: PETA.

Harmer, J (2001). The Practice of Language Teaching. London: Pearson Group Ltd.

Johnson, K. E. (2006). The socio-cultural turn and its challenges for second language teacher education. TESOL Quarterly 40: 235-257.

Juel, C. (1988). Learning to read and write: A longitudinal study of 54 children from first through fourth grade. Journal of Educational Psychology 80(4): 437-447.

Karimi and Jallivand (2014). The effect of peer and teacher scaffolding on the reading comprehension of EFL learners in asymmetrical and symmetrical groups. Islamic Azad University. The Journal of Teaching Language Skills (JILS), 5(4), winter 2014, Ser. 73/4

Kim, J,S. and White, T.G. (2008). Scaffolding voluntary summer reading for children in grades 3 to 5 : An experimental study.' Scientific Studies of Reading 12(1): 1-23.

Lantolf, J. P. (2006). 'Sociocultural theory and L2: State of the art. Studies in Second Language Acquisition 28: 67-109.

Mayer, R.E. (1996). History of Instructional Psychology. In: E., De Corte and F. E. Weinert (Eds).

Mesfin Derash. (2008).The practice of teaching reading in English at first cycle primary schools: grade four in focus (Unpublished M.A Thesis), School of Graduate Studies, Addis Ababa University.

Michael Daniel. (2003). The Effect of Primary English Readers on Reading Skills in Ethiopia (Unpublished $\mathrm{PhD}$ Dissertation), University of Pretoria: South Africa.

Ministry of Education (2009). General Education Quality Improvement Package (GEQIP) for Ethiopia. USAID.

MoE (2008). English Syllabus for Grades 1-4. Addis Ababa.

MoE (2008). Minimum Learning Competencies Grades 1-4. Addis Ababa: MoE.

MoE (2011). English for Ethiopia. Teacher's Guide Grade 4. Addis Ababa.

MoE (2011). English for Ethiopia. Student Book. Grade Four. Addis Ababa.

MoE (Ministry of Education). (2008). Ethiopian Third National Learning Assessment. Addis Ababa: Ministry of Education

Moore, A.S., DeStefano, J. and Adelman, E. (2010). Using opportunity to learn and early grade reading fluency to measure school effectiveness in Ethiopia, Guatemala and Nepal. The Academy for Educational Development (AED):EQUIP2.

NOE (National Organization for Examinations) (2004). Ethiopian Second National Learning Assessment of Grades 4 and 8 Students. Addis Ababa: NOE/MOE.

NOE (National Organization for Examinations) (2000). Ethiopian Baseline National Learning Assessment of Grades 4 and 8 Students. Addis Ababa: NOE/MOE.

National Reading Panel (2000). Teaching Children to Read: An Evidence Based Assessment of the Scientific Research Literature on Reading and its Implications for Reading Instruction; Reports of the subgroups. Washington DC; National Institute of Child Health and Human Development.

Oxford, R. (1997). Constructivism: Shape-shifting, substance, and teacher education. Peabod Journal of Education 72(1): 35-66.
Sci. Technol. Arts Res. J., April-June 2015, 4(2): 263-271

Philips, D.C. (1995). The good, the bad, the ugly: the many faces of constructivism. Educational Research 24(7): 512.

Piper, B. (2010). Ethiopia Early Grade Reading Assessment. Data analytic report: language and early learning. North Carolina: RTI International.

Rodgers, A. and Rodgers, E.M. (2004.) Scaffolding Literacy Instruction. Strategies for K-4 classrooms. Portsmouth: Heinemann.

Schalach, T.D. (2000). START comprehending: students and teachers actively reading text. The reading Teacher 62(1): 20-31.

Segalowitz, N. and Lightbown, P.M. (1999). Psycholinguistic approaches to SLA. Annual Review of Applied Linguistics 19: 43-63.

Smith, C., Stone, R. and Comings, J. (2012). Field Study Report: Literacy Policy and Practice in Ethiopia: Building on the TELL Programs and EGRA Results. http://dx.doi.org/10.1017/S0267190599190032 Retrieved 5 May 2014.

Snow, C., Burns, S. and Griffin, P. (1998). Preventing reading difficulties in young children. Washington, D.C.: National Academy Press.

Stanovich, K. (1986). Matthew effects in reading: Some consequence of individual differences in the acquisition of literacy. Reading Research Quarterly 21(4):360-407.

Taylor, B.M., Pearson, P.D., Clark, K. and Walpole, S. (2000). Effective Schools and Accomplished teachers: Lessons about primary grade reading instruction in lowincome schools. The Elementary School Journal 101: 121-165.

Transitional Government of Ethiopia (1994). Education and Training Policy: Addis Abeba:EMPDA.

Tsehay Jemberu (2012). Reading assessment of early grade children of five woredas in North Gonder of Amhara Region: A baseline data analytic report: Save the Children, Norway.

USAID/Ethiopia (2011). Reading for Ethiopia's Achievement Developed (READ). Technical assistance project. Presolicitation for Request for Proposals. Addis Ababa: USAID.

Walqui, A. (2006). Scaffolding instruction for English language learners: A conceptual framework. The International Journal of Bilingual Education and Bilingualism 9(2): 159-180.

Williams, M. and Burden, R.L. (1997). Psychology for language teachers: A social constructivist approach. Cambridge: Cambridge University Press.

Williams, E. (1984). Reading in the Language Classroom, London: Macmillan.

Wood, D., Bruner, J. and Ross, G. (1976). The Role of Tutoring in Problem-Solving. Journal of Child Psychology and Psychiatry 17: 89-100.

Vygotsky, L.S. (1978). Problems of Method . Cambridge, MA: Harvard University Press.

Vygotsky, L. S. (1978). Mind in society. The development of higher psychological processes. Cambridge MA: Harvard University Press.

Vygotsky, L.S. (1986). Thought and language. London, MA: MIT Press.

Zenebe Beyene (2000). An investigation of the minimum threshold level towards the end of the first cycle: Reading skills in focus (Unpublished M.A. thesis). Addis Ababa University. 